\title{
Anti-cytomegalovirus IgG antibody titer is positively associated with advanced T cell differentiation and coronary artery disease in end-stage renal disease
}

Feng-Jung Yang ${ }^{1,2}$, Kai-Hsiang Shu ${ }^{3,4}$, Hung-Yuan Chen ${ }^{3}$, I-Yu Chen ${ }^{3}$, Fang-Yun Lay ${ }^{3,4}$, Yi-Fang Chuang ${ }^{5}$, Chien-Sheng $\mathrm{Wu}^{3}$, Wan-Chuan $\mathrm{Tsai}^{3}$, Yu-Sen Peng ${ }^{3}$, Shih-Ping Hsu ${ }^{3}$, Chih-Kang Chiang ${ }^{6}$, George Wang ${ }^{7}$ and Yen-Ling Chiu ${ }^{1,3,8^{*}}$

\begin{abstract}
Background: Accumulating evidence indicates that persistent human cytomegalovirus (HCMV) infection is associated with several health-related adverse outcomes including atherosclerosis and premature mortality in individuals with normal renal function. Patients with end-stage renal disease (ESRD) exhibit impaired immune function and thus may face higher risk of HCMV-related adverse outcomes. Whether the level of anti-HCMV immune response may be associated with the prognosis of hemodialysis patients is unknown.

Results: Among 412 of the immunity in ESRD study (iESRD study) participants, 408 were HCMV seropositive and were analyzed. Compared to 57 healthy individuals, ESRD patients had higher levels of anti-HCMV IgG. In a multivariateadjusted logistic regression model, the log level of anti-HCMV IgG was independently associated with prevalent coronary artery disease $(\mathrm{OR}=1.93,95 \% \mathrm{Cl}=1.2 \sim 3.2, p=0.01)$ after adjusting for age, sex, hemoglobin, diabetes, calcium phosphate product and high sensitivity C-reactive protein. Levels of anti-HCMV IgG also positively correlated with both the percentage and absolute number of terminally differentiated CD8+ and CD4+ CD45RA+ CCR7- TEMRA cells, indicating that immunosenescence may participate in the development of coronary artery disease.

Conclusion: This is the first study showing that the magnitude of anti-HCMV humoral immune response positively correlates with T cell immunosenescence and coronary artery disease in ESRD patients. The impact of persistent HCMV infection should be further investigated in this special patient population.
\end{abstract}

Keywords: Cytomegalovirus, End-stage renal disease, Cardiovascular disease, Immunosenescence, Immunology

\section{Background}

Human cytomegalovirus (HCMV), a member of the $\beta$ herpesvirus family, contains a double-stranded DNA genome and persists in certain host cells indefinitely after primary infection [1]. Worldwide HCMV seroprevalence among women of reproductive age is about $45-100 \%$ [2]. Overall seroprevalence rate increases with age [3], reaching above $60 \%$ among people older than 50

\footnotetext{
* Correspondence: yenlingchiu@ntu.edu.tw

${ }^{1}$ Graduate Institute of Clinical Medicine, College of Medicine, National Taiwan University, Taipei, Taiwan

${ }^{3}$ Department of Internal Medicine, Far Eastern Memorial Hospital, New Taipei City, Taiwan

Full list of author information is available at the end of the article
}

and is considerably higher in Asian countries [4, 5]. Importantly, in addition to causing opportunistic infections, congenital infections, and mononucleosis, HCMV infection also possess long-term threats to immunocompetent individuals. Mounting evidence strongly suggests the implication of persistent HCMV infection in autoimmunity, cancer, poor response toward vaccination, cardiovascular disease and mortality [6-8].

Large-scale epidemiological studies and meta-analysis have suggested an association between HCMV seropositivity and cardiovascular disease [9, 10]. Earlier observations noted that HCMV seropositivity is associated with restenosis after coronary atherectomy [11]. HCMV can

(C) The Author(s). 2018 Open Access This article is distributed under the terms of the Creative Commons Attribution 4.0 International License (http://creativecommons.org/licenses/by/4.0/), which permits unrestricted use, distribution, and 
infect endothelial cells, which explains why its viral DNA is often found at sites of arterial disease [12]. HCMV could also contribute to cardiovascular disease via indirect mechanisms such as inducing systemic inflammation, cytokine release [13], and an increase in blood pressure [14]. Several studies based on HCMVspecific IgG titers also showed that higher IgG titers against HCMV, but not antibodies against herpes simplex virus 1 , are significantly associated with incident coronary artery events $[15,16]$. Since HCMV IgG increases in individuals with virus shedding [17] and its level positively correlates with HCMV-specific IgM [18], an increase of HCMV IgG during latency might indicate frequent or recent virus reactivation.

Of note, HCMV infection also leads to an imbalance of the $\mathrm{T}$ cell homeostasis, causing significant loss of naïve CD8+ T cells, accumulation of terminally differentiated memory CD4+ and CD8+ cells - premature aging of T cells, also known as "immunosenescence" [19, 20]. This perturbation of immune system not only causes impaired vaccine response [21], but also poor survival [22]. These terminally differentiated memory $\mathrm{T}$ cells might be preferentially recruited to vascular endothelium via upregulation of CX3CR1 and participate in the process of atherosclerosis [23, 24].

Cardiovascular mortality is the most important cause of death in ESRD (end stage renal disease) patients worldwide [25, 26]. ESRD patients exhibit a striking 20-400 fold higher risk of cardiovascular death compared to agematched healthy individuals. However, traditional cardiovascular disease risk factors only explain a relatively small proportion of such high cardiovascular disease burden [27]. Similar to healthy individuals, CMV seropositivity is related to the amount of terminally differentiated $\mathrm{T}$ cells in patients with ESRD $[28,29]$. To our knowledge, no study has attempted to study the relationship between the titer of HCMV-specific IgG with either immunosenescence or atherosclerotic heart disease in ESRD. We thus established the "immunity in ESRD" (iESRD) study, which is an ongoing longitudinal study aiming to investigate the impacts of immunological mechanisms on cardiovascular outcome in ESRD patients. The current study reports the association between HCMV IgG titer with immunosenescence and cardiovascular co-morbidities based on the baseline data from this cohort study.

\section{Methods}

\section{Participants}

The immunity in ESRD (iESRD) study is a cohort study investigating the effect of immunological factors on outcomes of hemodialysis patients. Patients and healthy controls were recruited from Far Eastern Memorial Hospital and National Taiwan University Hospital Yun Lin Branch. Far Eastern Memorial Hospital is located in
New Taipei City in northern Taiwan and National Taiwan University Yun Lin Branch is located in southern Taiwan. A total of 432 patients signed informed consent to join the study and were screened for eligibility. Those with recent hospitalization within three months, active or chronic infection requiring antibiotics, incomplete blood test results or poor blood samples quality were excluded, resulting in 412 patients enrolled in the iESRD study (198 from Far Eastern Memorial Hospital and 214 from National Taiwan University Hospital). Among these patients, 408 were CMV seropositive and were analyzed in the current study. Most patients (99.5\%) received hemodialysis at least $4 \mathrm{~h}$ per session, thrice a week; only two patients underwent twice a week hemodialysis. All patients were treated by their primary care nephrologists according to the Kidney Disease Outcomes Quality Initiative (KDOQI) guidelines.

\section{Data collections and laboratory exams}

Blood samples were collected before the start of hemodialysis sessions in the middle of week. In addition to hematological and biochemical tests, peripheral blood mononuclear cells (PBMC) were sampled. Intactparathyroid hormone (i-PTH) immunoradiometric assay (Cisbio) and high sensitive C-reactive protein (hs-CRP) nephelometry (Siemens) were also tested. By history taking and detailed chart reviews, baseline co-morbidities and clinical laboratory data were recorded. HCMVspecific IgG titer was measured by ELISA (Roche Elecsys assay) at Far Eastern Memorial Hospital. Plasma level of inflammatory cytokines were measured using the human IL-6 Quantikine HS ELISA kit and human TNF $\alpha$ Quantikine ELISA Kit from R\&D systems.

\section{Immunophenotyping and multicolor flow cytometry}

After blood collection, peripheral blood mononuclear cells (PBMCs) were immediately isolated by Ficoll-Paque PLUS gradient centrifugation following the manufacturer's protocol (GE Healthcare). For flow cytometry analysis, briefly, singlets were collected by forward scatter area and height. CD3-AF700 (clone UCHT1, BioLegend) was used to identify $\mathrm{CD} 3+\mathrm{T}$ cells from the lymphocytes gated by forward and side scatter properties. CD4+ and CD8+ T cells were determined by CD4-PerCP-Cy5.5 and CD8-APC-Cy7 (clone OKT4 and SK1, BioLegend) respectively, and the T cell differentiation states were determined by CCR7-APC, CD45RA-Alexa488 (clone G043H7 and HI100, BioLegend) and CD28-PE-Cy7 (clone 28.2, eBioscience).

Monocyte staining was performed according to previous studies performed by Zawada et al., which indicated that a pan-monocyte marker such as CD86 is necessary to correctly enumerate monocyte subsets [30]. After gating on the forward scatter/side scatter, monocytes were determined by expression of CD86-PE (clone IT2.2, 
eBioscience), and were further classified as classical (CD14 $++\mathrm{CD} 16-)$, intermediate (CD14++CD16+), and nonclassical $(\mathrm{CD} 14+\mathrm{CD} 16++)$ by CD14-FITC and CD16APC (clone M5E2, Biolegend and clone 3G8, eBioscience). In general, the percentage calculated for a specific immune cell subset refers to the percentage of a specific cell subset among the mother population on flow cytometry.

\section{Cardiovascular co-morbidities}

Medical comorbidity status of all patients were determined by careful review of medical history and radiological reports. The documented coronary artery disease (CAD) was defined as either 1) $>50 \%$ stenosis of at least one coronary artery on coronary angiography or 2) documented perfusion defect(s) on stressed cardiac nuclear scan. Cardiovascular disease (CVD) was defined as having documented $\mathrm{CHF}, \mathrm{CAD}$, stroke and/or peripheral arterial disease (PAOD). Congestive heart failure (CHF) was diagnosed clinically as a syndrome in which patients have symptoms and signs resulting from an abnormal cardiac structure or function by cardiologists.

\section{Statistical analyses}

Patient characteristics were described as mean \pm standard deviation for continuous variables and frequency for categorical variables. These variables were analyzed by ANOVA and Chi-square test, respectively. Pearson correlation was applied to evaluate the correlation of logtransformed HCMV-specific IgG with immune cell subsets frequencies and absolute cell numbers.

Binary and ordered logistic regression models were used to calculate the predictive value of HCMV IgG level on cardiovascular co-morbidities. Univariate logistic regression was performed to calculate the $p$ for trend value for determining the relationship between HCMV IgG quintiles and individual medical co-morbidity. Multivariableadjusted logistic regression models, including age, gender, diabetes mellitus, albumin, hemoglobin, calcium phosphate product and high sensitivity-CRP were used to investigate the association between HCMV IgG level and comorbidities. All statistical tests were two-tailed, and a $p$ value of less than 0.05 was considered be significant. The statistical analyses were performed with SPSS Version 25 (IBM) and STATA version 14.2 (StataCorp).

\section{Results}

HCMV IgG levels in ESRD patients are elevated compared to control individuals

First, we compared HCMV IgG levels between 408 CMV seropositive ESRD patients from the iESRD cohort and 57 CMV seropositive healthy individuals. The age of ESRD patients and healthy individuals were not statistically different (mean \pm SD, ESRD: $62.0 \pm 11.9$; Healthy: $58.9 \pm 6.8$ ). Despite general belief of a more immunosuppressed state, ESRD patients exhibit significantly higher levels of HCMV IgG compared to healthy individuals (Fig. 1a, medium $=391.9 \mathrm{U} / \mathrm{mL}$, IQR $181.5 \sim$ 818.5 versus medium $=305.8 \mathrm{U} / \mathrm{mL}$, IQR $132.1 \sim 624.1$ ). We further stratified HCMV IgG levels into quintiles and investigated the differences in demographic, clinical and laboratory data among groups. As Table 1 shows, patients in the highest HCMV IgG quintile tend to be older, have lower levels of hemoglobin, creatinine, phosphate and normalized protein catabolic rate, although most of these differences were not statistically significant.

\section{Elevated HCMV IgG levels is not associated with systemic inflammation in ESRD}

Since premature aging and systemic inflammation are important features of ESRD patients [31], we tested the associations between HCMV-specific IgG level with chronological age and circulatory inflammatory markers. We found a significant association between age and logtransformed HCMV IgG level $(\mathrm{R}=0.15, p$ value $=0.003)$. Nevertheless, there was no relationship between HCMV IgG level and systemic inflammation, as measured by high-sensitivity C-reactive protein levels, TNF $\alpha$ levels and IL- 6 (by Pearson correlation, all $p$ value $>0.05$ ). It has been suggested that elevated HCMV IgG level in asymptomatic individuals reflects virus reactivation and shedding [17]. As a result, augmented humoral response toward CMV in ESRD patients may be a unique immunological phenomenon that reflects aging and subclinical viral reactivation but not simply a status of nonspecific systemic inflammation.

\section{Higher CMV-lgG level is associated with advanced T cell differentiation but not monocyte subset distribution in ESRD}

Previous studies indicated that certain $\mathrm{T}$ cell and monocyte subsets [32-34] are associated with cardiovascular disease and/or atherosclerosis. Although it is known that CMV infection profoundly affects the adaptive human immune system [35, 36], much less is known about the effect of CMV infection on monocytes. We performed peripheral blood $\mathrm{T}$ cell and monocyte immunophenotyping in all the 408 CMV seropositive iESRD participants and tested the relationship between log-transformed HCMV-specific IgG level with distinct immune subsets, in either relative (percentage of mother population) or absolute (absolute cell number per $\mu \mathrm{l}$ of blood) terms. The representative multicolor flow cytometry staining is shown in Fig. 1b. Human T cells were separated into the CCR7+ CD45RA+ $\mathrm{T}_{\mathrm{NAIVE}}$ subset, the CCR7+ CD45RA$\mathrm{T}_{\mathrm{CM}}$ subset, the CCR7-CD45RA- $\mathrm{T}_{\mathrm{EM}}$ subset and the CCR7-CD45RAT $T_{\text {EMRA }}$ subset and the $\mathrm{T}_{\mathrm{EM}}$ and $\mathrm{T}_{\mathrm{EMRA}}$ subsets are known to increase in HCMV-infected individuals. As shown in Table 2, stronger humoral response 


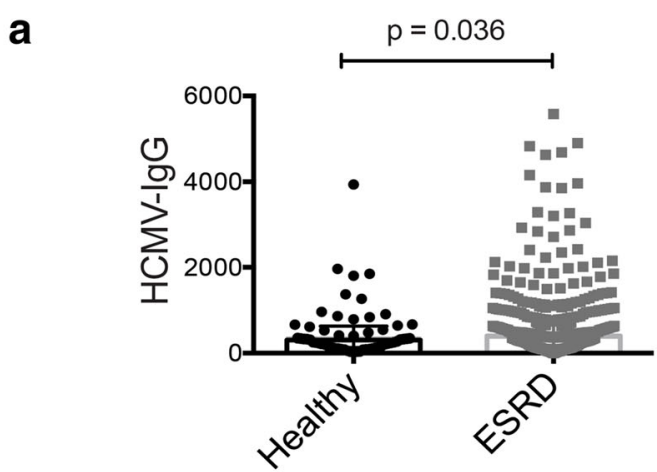

b
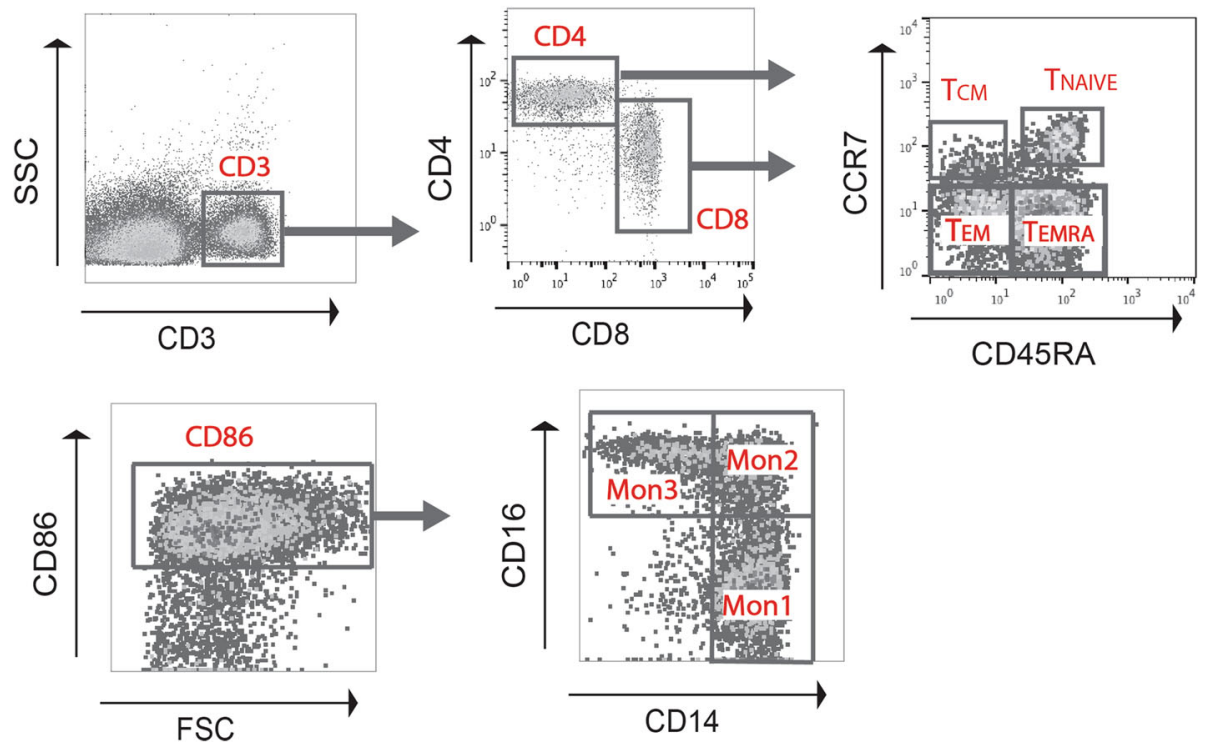

Fig. 1 a Levels of HCMV-specific $\operatorname{lgG}(\mathrm{U} / \mathrm{mL})$ were compared between healthy individuals and ESRD patients. The lines indicate medium and interquartile range. Statistical calculation of $\mathrm{p}$ value was performed using Mann-Whitney $U$ non-parametric test. $\mathbf{b}$ Representative multicolor flow cytometry staining of T cell subsets (above) and monocyte subsets (below). $T_{\text {NAIVE, }}$ naïve $T$ cells; $T_{C M}$, central memory $T$ cells; $T_{E M}$, effector memory $T$ cells; $T_{E M R A}$, effector memory T cells with RA expression. Mon1, classical monocytes; Mon2, intermediate monocytes; Mon3, non-classical monocytes

against HCMV is associated with significant disturbance in the adaptive $\mathrm{T}$ cell homeostasis in ESRD. Patients with higher titer of HCMV-specific IgG exhibit lower percentages of CD4+ and CD8+ T cells but higher percentages of CD4 + CD28null and CD8+ terminally differentiated $\mathrm{T}_{\mathrm{EMRA}}$ cells. Similar trends were observed when absolute cell number of each $\mathrm{T}$ cell subsets was analyzed and were also present in healthy controls (Additional file 1: Table S1). Higher titer of HCMV-specific IgG was associated with increased numbers of advanced differentiated CD4+ T cells. In contrast, HCMV-specific IgG level did not correlate with any specific monocyte subset changes. Previous studies in the literature only have compared $\mathrm{T}$ cell differentiation between HCMV seropositive and seronegative individuals. To our knowledge, this is the first description that the magnitude of humoral response against HCMV positively correlates with level of advanced terminal differentiation of both CD4+ and CD8+ T cells in ESRD patients. Overall, these results support the hypothesis that less-well controlled HCMV infection in ESRD patients drives the host adaptive immune system toward advanced terminal differentiation.

\section{Cardiovascular co-morbidities stratified by HCMV IgG levels}

As reviewed in the introduction, previous studies performed on non-renal failure individuals have implicated HCMV infection in atherosclerotic vascular disease [37, 38]. As shown above, HCMV IgG level positively associates with the accumulation of terminally differentiated immunosenescent $\mathrm{T}$ cells. These cells have high atherogenic potentials, characterized by high CX3CR1 expression (thus allowing binding to injured endothelium) and capability of inducing endothelium damage [23, 24], eventually leading to atherosclerotic vascular diseases. These effector cells are 
Table 1 Baseline demographic, clinical and laboratory measurements stratified by HCMV-specific IgG titer

\begin{tabular}{|c|c|c|c|c|c|c|}
\hline & 1 st Quintile $(n=73)$ & 2nd Quintile $(n=75)$ & 3rd Quintile $(n=80)$ & 4th Quintile $(n=87)$ & 5th Quintile $(n=93)$ & $p$ value \\
\hline HCMV-lgG (U/ml) & $76.9(35.4)$ & 214.1(50.9) & $367.6(48.5)$ & 618.4(129) & 1813(1079) & $<0.001^{*}$ \\
\hline Age $(y r)$ & $59.3(11.4)$ & $62.9(13.4)$ & $61.2(11.5)$ & $62.4(12.0)$ & $63.8(11.0)$ & 0.16 \\
\hline Male (\%) & 56 & 49 & 51 & 52 & 46 & 0.79 \\
\hline Diabetes (\%) & 55 & 31 & 30 & 46 & 41 & 0.07 \\
\hline Dialysis vintage (yr) & $4.7(3.5)$ & $6.6(4.9)$ & $6.1(4.7)$ & $6.4(4.8)$ & $6.7(6.2)$ & 0.11 \\
\hline Albumin (g/dl) & $4.1(0.33)$ & $4.0(0.40)$ & $4.1(0.30)$ & $4.0(0.48)$ & $4.0(0.42)$ & 0.09 \\
\hline WBC (K/ul) & $6.4(2.0)$ & $6.2(2.0)$ & $6.3(1.7)$ & $6.6(2.2)$ & $6.5(2.2)$ & 0.75 \\
\hline Hemoglobin (g/dl) & 11.1(1.3) & $10.7(1.3)$ & $11.3(1.1)$ & 10.8(1.6) & $10.6(1.4)$ & $0.01^{*}$ \\
\hline BUN (mg/dl) & $81.1(20.3)$ & $79.5(20.3)$ & $78.9(20.8)$ & $79.5(20.6)$ & $76.8(18.1)$ & 0.72 \\
\hline Creatinine (mg/dl) & $11.7(2.3)$ & $11.1(2.7)$ & $11.9(2.4)$ & $10.7(2.4)$ & $10.6(2.3)$ & $0.001^{*}$ \\
\hline T-Cholesterol (mg/dl) & $145(38.1)$ & $151(34.0)$ & 159(36.1) & $154(42.6)$ & 148(33.7) & 0.15 \\
\hline Triglyceride (mg/dl) & 148(93.9) & 139(92.1) & $146(100.3)$ & 160(94.0) & 143(92.1) & 0.71 \\
\hline intact-PTH (pg/ml) & $344(37.1)$ & 405(46.9) & 307(38.3) & 308(37.8) & $443(58.1)$ & 0.12 \\
\hline Calcium (mg/dl) & $9.2(0.7)$ & $9.4(0.9)$ & $9.4(0.7)$ & $9.3(0.8)$ & $9.4(0.8)$ & 0.87 \\
\hline Phosphate (mg/dl) & $5.2(1.5)$ & $5.2(1.5)$ & $5.1(1.2)$ & $4.7(1.4)$ & $4.6(1.3)$ & $0.005^{*}$ \\
\hline Kt/N (Gotch) & $1.35(0.2)$ & $1.41(0.2)$ & $1.40(0.2)$ & $1.38(0.2)$ & $1.39(0.2)$ & 0.48 \\
\hline nPCR (g/Kg) & $1.15(0.3)$ & $1.23(0.4)$ & $1.23(0.3)$ & $1.21(0.3)$ & $1.11(0.7)$ & 0.40 \\
\hline
\end{tabular}

Demographic and clinic data were compared between groups of CMV-lgG quintiles in 408 ESRD patients. Quintile cut-offs were derived from HCMV-lgG levels of healthy controls. Values were expressed as mean (SD)

$n P C R$ normalized protein catabolic rate

${ }^{*} p$ value $<0.05$

Table 2 Correlations between HCMV-specific lgG titer with levels of immune cells among ESRD patients

\begin{tabular}{|c|c|c|c|c|}
\hline & \multicolumn{2}{|c|}{ Cell frequency } & \multicolumn{2}{|c|}{ Absolute cell number } \\
\hline & $\bar{R}$ & $p$ value & $\bar{R}$ & $p$ value \\
\hline \multicolumn{5}{|l|}{ CD4+ T cells } \\
\hline Naïve T cells & -0.33 & NS & -0.05 & NS \\
\hline Stem Memory T cells & -0.03 & NS & -0.12 & NS \\
\hline Central Memory T cells & -0.12 & $0.013^{*}$ & -0.13 & $0.007^{*}$ \\
\hline Effector Memory T cells & 0.14 & $0.006^{*}$ & 0.06 & NS \\
\hline Terminally Differentiated T cells & 0.11 & $0.035^{*}$ & 0.010 & $0.003^{*}$ \\
\hline CD28 null cells & 0.15 & $0.002^{*}$ & 0.12 & $0.02^{*}$ \\
\hline \multicolumn{5}{|l|}{ CD8+ T cells } \\
\hline Naïve T cells & -0.15 & $0.003^{*}$ & -0.18 & $<0.001^{*}$ \\
\hline Stem Memory T cells & 0.006 & NS & -0.16 & $0.002^{*}$ \\
\hline Central Memory T cells & -0.10 & $0.039^{*}$ & -0.15 & $0.003^{*}$ \\
\hline Effector Memory T cells & -0.03 & NS & -0.03 & NS \\
\hline Terminally Differentiated T cells & 0.20 & $<0.001^{*}$ & 0.09 & 0.07 \\
\hline \multicolumn{5}{|l|}{ Monocytes } \\
\hline Classical Monocytes & 0.02 & NS & 0.04 & NS \\
\hline Intermediate Monocytes & 0.01 & NS & 0.04 & NS \\
\hline Non-Classical Monocytes & -0.03 & NS & -0.006 & NS \\
\hline
\end{tabular}

Pearson correlation was applied to investigate the relationship between log transformed HCMV-specific lgG titer and immune cell levels, including percentages as well as absolute cell counts of naïve $\left(T_{\text {NAIVE }}\right)$, stem cell memory $\left(T_{S C M}\right)$, central memory $\left(T_{C M}\right)$, effector memory $\left(T_{E M}\right)$, terminally differentiated $\left(T_{E M R A}\right)$ subsets and three monocyte subsets (classical monocytes, intermediate monocytes, non-classical monocytes)

NS non-significant, $P$ value $>0.1$

${ }^{*} p$ value $<0.05$ 
likely to be HCMV-specific, and we previously have shown that HCMV-specific cells are of high degree of cytokine production as well as cytotoxic functions [39]. We thus compared the percentage of patients with various cardiovascular complications among patients belonging to different HCMV IgG quintiles. As shown in Fig. 2, patients within the highest IgG quintile had the highest prevalence of congestive heart failure (CHF), coronary artery disease (CAD), and history of old myocardial infarction. However, the prevalence of stroke (including both ischemic and hemorrhagic stroke) was not associated with higher of HCMV IgG levels (data not shown). When the relationship between HCMV IgG quintile and individual comorbidity were analyzed in regression models, higher IgG quintile was significantly associated with CAD (odds ratio $=1.25$, $p$ for trend $=0.006$ ), CHF (odds ratio $=1.22, p$ for trend $=0.036$ ), and history of MI (odds ratio $=1.48, p$ for trend $=0.014$ ), but not with stroke (odds ratio $=0.84, p$ for trend $=0.19$ ) and CVD (odds ratio $=1.13$, p for trend $=0.32$ ).

HCMV IgG level independently associates with prevalent CAD We next tested the independent association of HCMVspecific IgG level with CAD and CVD. Besides CAD, other individual co-morbidities were not tested because the percentages of patient with those co-morbidities were much lower. As shown in Table 3, higher HCMV-specific IgG quintile independently associated with prevalent CAD in both regression models, after adjusting for age, gender and other traditional and non-traditional cardiovascular risk factors. Nevertheless, the independent association between CVD and CMV IgG was not statistically significant. Similarly results were found when log-transformed IgG level was used in the regression model instead of HCMV IgG quintile (Additional file 1: Table S2).

\section{Discussion}

In the general population, HCMV infection is related to many adverse clinical conditions; atherosclerotic vascular complications are by far one of the best studied [37,
40]. In this study, we successfully demonstrated the association between higher anti-HCMV IgG titer in ESRD patients and higher risk for CAD, and suggested a potential mechanistic link between subclinical HCMV reactivation, aggravated $\mathrm{T}$ cell effector differentiation and coronary artery disease in this patient population. Our results indicate that it is necessary to continue investigating the long-term impact of immune response against HCMV in ESRD in longitudinal studies.

ESRD patients are characterized by a marked status of chronic systemic inflammation [41]. Interestingly, although HCMV IgG titer does not correlate with systemic inflammation in our study, previous studies indicate persistent HCMV infection has stronger impact in individuals with chronic inflammation. In a study involving 989 non-renal patients with CAD [42], HCMV seropositivity was independently associated with a 3.2fold increase in risk of future cardiac death only in patients with high IL-6 levels, whereas in individuals without IL-6 elevation, HCMV had no effect on cardiac mortality. Another study showed that HCMV seropositivity in combination with elevated hsCRP is a strong, independent predictor of future cardiac death [38]. Because chronic inflammation is a pertinent feature of renal failure patients, ESRD patients might be prone to suffer from HCMV-associated adverse effects on cardiovascular complications.

Our study also found that HCMV-specific IgG level positively correlated with advanced $\mathrm{T}$ cell differentiation. Cantisan et al. had found that the loss of CD27 and CD28 on HCMV-specific T cells post solid organ transplantation correlated with HCMV replication and this process was age-dependent [43]. Advanced T cell differentiation has been found in ESRD seropositive for HCMV [44], and ESRD patients also demonstrate a shift in their $\mathrm{T}$ cell receptor $\mathrm{V} \beta$ chain repertoire [45], which is correlated with age. It remains unknown if level of HCMV-specific IgG correlates with V $\beta$ diversity in ESRD patients.

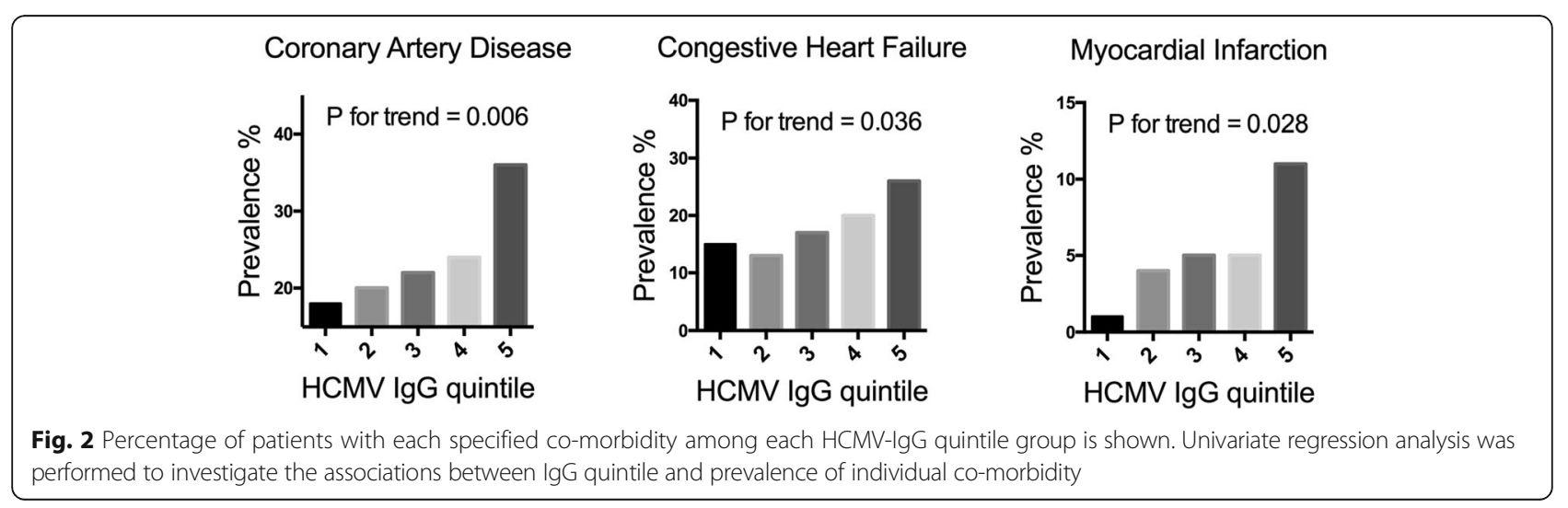


Table 3 Association between HCMV-specific lgG quintile and coronary artery disease or cardiovascular disease

\begin{tabular}{|c|c|c|}
\hline Variables in model (independent variable: CAD) & OR $(95 \% \mathrm{Cl})$ & $P$ value \\
\hline \multicolumn{3}{|l|}{ Model 1} \\
\hline Age & $1.03(1.01-1.05)$ & $0.01^{*}$ \\
\hline Gender (Male) & $1.43(0.90-2.29)$ & 0.14 \\
\hline Diabetes & $2.90(1.82-4.64)$ & $<0.001^{*}$ \\
\hline HCMV-specific lgG quintile & $1.25(1.06-1.48)$ & $0.007^{*}$ \\
\hline \multicolumn{3}{|l|}{ Model 2} \\
\hline Age & $1.04(1.01-1.06)$ & $0.003^{*}$ \\
\hline Gender (Male) & $1.39(0.86-2.25)$ & 0.18 \\
\hline Diabetes & $2.87(1.77-4.64)$ & $<0.001^{*}$ \\
\hline Albumin (g/dL) & $1.44(0.67-3.12)$ & 0.35 \\
\hline Hemoglobin (g/dL) & $1.17(0.97-1.43)$ & 0.10 \\
\hline $\mathrm{Ca} \times \mathrm{P}$ product $\left(\mathrm{mg}^{2} / \mathrm{dL}^{2}\right)$ & $1.01(1.0-1.03)$ & 0.27 \\
\hline hs-CRP (mg/dL) & $1.37(1.12-1.67)$ & $0.002^{*}$ \\
\hline HCMV-specific lgG quintile & $1.27(1.07-1.51)$ & $0.007^{*}$ \\
\hline Variables in model (independent variable: CVD) & OR $(95 \% \mathrm{Cl})$ & $P$ value \\
\hline \multicolumn{3}{|l|}{ Model 1} \\
\hline Age & $1.04(1.02-1.06)$ & $<0.001^{*}$ \\
\hline Gender (Male) & $1.36(0.88-2.11)$ & 0.17 \\
\hline Diabetes & $2.88(1.86-4.48)$ & $<0.001^{*}$ \\
\hline HCMV-specific lgG quintile & $1.13(0.97-1.32)$ & 0.13 \\
\hline \multicolumn{3}{|l|}{ Model 2} \\
\hline Age & $1.03(1.02-1.06)$ & $<0.001^{*}$ \\
\hline Gender (Male) & $1.32(0.84-2.08)$ & 0.22 \\
\hline Diabetes & $2.84(1.80-4.44)$ & $<0.001^{*}$ \\
\hline Albumin (g/dL) & $1.07(0.52-2.16)$ & 0.87 \\
\hline Hemoglobin (g/dL) & $1.20(1.00-1.44)$ & $0.048^{*}$ \\
\hline $\mathrm{Ca} \times \mathrm{P}$ product $\left(\mathrm{mg}^{2} / \mathrm{dL}^{2}\right)$ & $1.01(0.99-1.03)$ & 0.32 \\
\hline hs-CRP (mg/dL) & $1.32(1.08-1.60)$ & $0.005^{*}$ \\
\hline HCMV-specific lgG quintile & $1.13(0.96-1.33)$ & 0.13 \\
\hline
\end{tabular}

Multivariable-adjusted logistic regression models, including age, gender, diabetes mellitus, albumin, hemoglobin, calcium phosphate product and high sensitivity-CRP were used to investigate the independent association between HCMV IgG quintile and co-morbidities. * $p$ value $<0.05$

Only few cohort studies have investigated the role of HCMV-specific IgG in cardiovascular mortality in the general population. In the population-based Atherosclerosis Risk in Community (ARIC) study, people with the highest level of anti-HCMV IgG exhibited a 1.76-fold higher risk for coronary artery disease during a five-year follow-up when compared to the lowest level group [16]. People with diabetes are also affected by HCMV infection, with a relative risk of 9.2. In another population-based study (EPICNorfolk), individuals with the highest level of anti-HCMV IgG also had a 1.22-fold higher risk for ischemic heart disease when compared to seronegative individuals [15]. Our current study in ESRD patients indicates elevated HCMV IgG titer is related to coronary artery disease and history of myocardial infarction, but we did not find significant association between IgG titer and stroke. Interestingly, while CMV viral DNA is frequently found in coronary artery atherosclerotic plaques, some studies had reported the lack of CMV DNA in carotid artery plaques [46].

The exact mechanisms by which persistent HCMV infection results in higher cardiovascular mortality remain elusive [47], but the accumulation of terminally differentiated $\mathrm{T}$ cells could be a plausible mechanism. Our recent studies showed anti-HCMV IgG level positively correlates with the total size of virus-specific $T$ cell pool [39] and inversely correlated with $\mathrm{T}$ cell receptor diversity [48] in individuals without renal disease. A recent report further showed that HCMV-specific senescent $\mathrm{T}$ cells are 
associated with arterial stiffness [49]. After adherence to activated vascular endothelium via CXCR3, these cytotoxic $\mathrm{T}$ cells further participate in atherogenesis by directly causing endothelial damage [24] and they also secrete high level of TNF $\alpha$ [39], the critical cytokine to activate macrophages. Intermediate monocytes $(\mathrm{CD} 14++\mathrm{CD} 16+)$ are known to participate in atherosclerosis [50] but we discovered that HCMV-specific IgG did not affect the level of intermediate monocyte, indicating a different mechanism for monocyte activation in ESRD patients. Since our study did not measure the extent of atherosclerosis or arteriosclerosis, we could not analyze the impact of immune response on these pathological parameters separately. Animal studies of MCMV infection in renal failure mice will help to provide more detailed information.

There are additional limitations with this study. First, because the study is built on cross-sectional data only, we could not yet establish the causal relationship between levels of anti-HCMV IgG and cardiovascular complications. In addition, it remains technically difficult to detect subclinical HCMV reactivation, as attempts to analyze serum viral load turned out negative for all of our patients (data not shown). As a result, the mechanism for variable HCMV-specific IgG titers in ESRD patients is still unknown. Finally, it remains unknown if HCMV-specific IgG level is dynamic or stable in ESRD patients and follow-up data from our ongoing iESRD cohort will provide insight into this question.

In conclusion, our current study is the first to demonstrate that anti-HCMV IgG titer is elevated in ESRD patients with persistent HCMV infection and associates with prevalent coronary artery disease. The effect is significant and independent of traditional or nontraditional cardiovascular risk factors, including inflammation. Level of HCMV IgG also positively correlates with $\mathrm{T}$ cell terminal differentiation, which could serve as the mediator for this association. This implies a pathogenic role of HCMV reactivation in ESRD patients, and further studies are warranted to continue investigating the long-term effects of persistent HCMV infection in this susceptible population.

\section{Conclusions}

Our study indicates that anti-HCMV specific IgG is elevated in ESRD patients, who are at high risk of CAD. The elevation of HCMV-specific IgG positively correlates with advanced $\mathrm{T}$ cell differentiation but does not with monocyte subset homeostasis. In ESRD patients, HCMV-specific IgG level is independently associated with prevalent of CAD. The impact of persistent HCMV infection on CAD should be further investigated in this patient population.

\section{Additional file}

Additional file 1: Table S1. Correlations between HCMV-specific lgG titer with levels of immune cells among healthy individuals. Table S2. Associations between log-transformed HCMV-specific lgG level with coronary artery disease and cardiovascular disease. (DOCX 26 kb)

\begin{abstract}
Abbreviations
CAD: Coronary artery disease; CHF: Congestive heart failure; CVD: Cardiovascular disease; ESRD: End-stage renal disease; HCMV: Human cytomegalovirus
\end{abstract}

\section{Acknowledgements}

The authors thank Ms. Priscilla Tsai for her expertise and assistance with multicolor flow cytometry.

\section{Funding}

This work was supported by Far Eastern Memorial Hospital grant FEMH-2015C-007, FEMH-NTUH joint grant-104-FTN-17, Ministry of Science and Technology grant 104-2314-B-418-017, and National Taiwan University Hospital Yunlin Branch grant NTUHYL105.X010, NTUHYL106.X009.

Availability of data and materials

Original flow cytometry data are available upon request.

\section{Authors' contributions}

FJY, KHS and YLC designed the study; FJY, HYC, WCT, YSP, SPH and YLC recruited study participants; IYC, FYL and KHS performed the experiments and multicolor flow cytometry; YFC and FJY performed statistical analyses; FJY, KHS and YLC wrote the manuscript; CSW and GW provided expert opinions for study design, execution and edited the manuscript; all authors participated in discussion, interpretation and final preparation of the manuscript. All authors read and approved the final manuscript.

Ethics approval and consent to participate

The study is approved by both FEMH and NTUH's institutional ethical committees (FEMH 103084-E and NTUYL 201511092 RINA) and informed consent was acquired from all participants.

Consent for publication

All authors consent to the publication of this final version of manuscript.

Competing interests

Non-declared. The authors declare that the research was conducted in the absence of any commercial or financial relationships that serves as a potential conflict of interest. The results presented in this paper have not been published previously in whole or part, except in abstract format.

\section{Publisher's Note}

Springer Nature remains neutral with regard to jurisdictional claims in published maps and institutional affiliations.

\section{Author details}

${ }^{1}$ Graduate Institute of Clinical Medicine, College of Medicine, National Taiwan University, Taipei, Taiwan. ${ }^{2}$ Department of Internal Medicine, National Taiwan University Hospital Yun Lin Branch, Douliu, Taiwan. ${ }^{3}$ Department of Internal Medicine, Far Eastern Memorial Hospital, New Taipei City, Taiwan. ${ }^{4}$ Graduate Institute of Immunology, College of Medicine, National Taiwan University, Taipei, Taiwan. ${ }^{5}$ Institute of Public Health, School of Medicine, National Yang Ming University, Taipei, Taiwan. ${ }^{6}$ Department of Medicine, National Taiwan University Hospital, Taipei, Taiwan. ${ }^{7}$ Biology of Healthy Aging Program, Division of Geriatric Medicine and Gerontology, Johns Hopkins University School of Medicine, Baltimore, MD, USA. ${ }^{8}$ Graduate Program in Biomedical Informatics, Yuan Ze University, Taoyuan City, Taiwan. 


\section{Received: 15 March 2018 Accepted: 9 May 2018}

\section{Published online: 02 July 2018}

\section{References}

1. Dolan A, Cunningham C, Hector RD, Hassan-Walker AF, Lee L, Addison C, Dargan DJ, McGeoch DJ, Gatherer D, Emery VC, et al. Genetic content of wild-type human cytomegalovirus. J Gen Virol. 2004;85:1301-12.

2. Cannon MJ, Schmid DS, Hyde TB. Review of cytomegalovirus seroprevalence and demographic characteristics associated with infection. Rev Med Virol. 2010;20:202-13.

3. Staras SA, Dollard SC, Radford KW, Flanders WD, Pass RF, Cannon MJ. Seroprevalence of cytomegalovirus infection in the United States, 19881994. Clin Infect Dis. 2006;43:1143-51.

4. Taniguchi K, Watanabe N, Sato A, Jwa SC, Suzuki T, Yamanobe Y, Sago H, Kozuka K. Changes in cytomegalovirus seroprevalence in pregnant Japanese women-a 10-year single center study. J Clin Virol. 2014;59:192-4.

5. Chen HY, Chiang CK, Wang HH, Hung KY, Lee YJ, Peng YS, Wu KD, Tsai TJ, Cognitive-behavioral therapy for sleep disturbance in patients undergoing peritoneal Dialysis: a pilot randomized controlled trial. Am J Kidney Dis. 2008:52(2):314-23.

6. Spyridopoulos I, Martin-Ruiz C, Hilkens C, Yadegarfar ME, Isaacs J, Jagger C, Kirkwood T, von Zglinicki T. CMV seropositivity and T-cell senescence predict increased cardiovascular mortality in octogenarians: results from the Newcastle 85+ study. Aging Cell. 2015;15(2):389-92.

7. Wang GC, Kao WH, Murakami P, Xue QL, Chiou RB, Detrick B, McDyer JF, Semba RD, Casolaro V, Walston JD, Fried LP. Cytomegalovirus infection and the risk of mortality and frailty in older women: a prospective observational cohort study. Am J Epidemiol. 2010;171:1144-52.

8. Aiello AE, Chiu YL, Frasca D. How does cytomegalovirus factor into diseases of aging and vaccine responses, and by what mechanisms? Geroscience. 2017:39:261-71.

9. Simanek AM, Dowd JB, Pawelec G, Melzer D, Dutta A, Aiello AE. Seropositivity to cytomegalovirus, inflammation, all-cause and cardiovascular disease-related mortality in the United States. PLoS One. 2011;6:e16103.

10. Wang H, Peng G, Bai J, He B, Huang K, Hu X, Liu D. Cytomegalovirusinfection and relative risk of cardiovascular disease (ischemic heart disease, stroke, and cardiovascular death): a meta-analysis of prospective studies up to 2016. J Am Heart Assoc. 2017;6:e005025.

11. Zhou YF, Leon MB, Waclawiw MA, Popma JJ, Yu ZX, Finkel T, Epstein SE. Association between prior cytomegalovirus infection and the risk of restenosis after coronary atherectomy. N Engl J Med. 1996;335:624-30

12. Izadi M, Fazel M, Saadat SH, Nasseri MH, Ghasemi M, Dabiri H, Aryan RS, Esfahani AA, Ahmadi A, Kazemi-Saleh D, et al. Cytomegalovirus localization in atherosclerotic plaques is associated with acute coronary syndromes: report of 105 patients. Methodist Debakey Cardiovasc J. 2012;8:42-6.

13. Compton T, Kurt-Jones EA, Boehme KW, Belko J, Latz E, Golenbock DT, Finberg RW. Human cytomegalovirus activates inflammatory cytokine responses via CD14 and toll-like receptor 2. J Virol. 2003;77:4588-96.

14. Cheng J, Ke Q, Jin Z, Wang H, Kocher O, Morgan JP, Zhang J, Crumpacker CS. Cytomegalovirus infection causes an increase of arterial blood pressure. PLoS Pathog. 2009;5:e1000427.

15. Gkrania-Klotsas E, Langenberg C, Sharp SJ, Luben R, Khaw KT, Wareham NJ. Higher immunoglobulin $\mathrm{G}$ antibody levels against cytomegalovirus are associated with incident ischemic heart disease in the population-based EPIC-Norfolk cohort. J Infect Dis. 2012;206:1897-903.

16. Sorlie PD, Nieto FJ, Adam E, Folsom AR, Shahar E, Massing M. A prospective study of cytomegalovirus, herpes simplex virus 1 , and coronary heart disease: the atherosclerosis risk in communities (ARIC) study. Arch Intern Med. 2000:160:2027-32.

17. Mehta SK, Stowe RP, Feiveson AH, Tyring SK, Pierson DL. Reactivation and shedding of cytomegalovirus in astronauts during spaceflight. J Infect Dis. 2000;182:1761-4.

18. McVoy MA, Adler SP. Immunologic evidence for frequent age-related cytomegalovirus reactivation in seropositive immunocompetent individuals. J Infect Dis. 1989;160:1-10.

19. Wertheimer AM, Bennett MS, Park B, Uhrlaub JL, Martinez C, Pulko V, Currier NL, Nikolich-Zugich D, Kaye J, Nikolich-Zugich J. Aging and cytomegalovirus infection differentially and jointly affect distinct circulating T cell subsets in humans. J Immunol. 2014;192:2143-55.

20. Weinberger B, Lazuardi L, Weiskirchner I, Keller M, Neuner C, Fischer KH Neuman B, Wurzner R, Grubeck-Loebenstein B. Healthy aging and latent infection with CMV lead to distinct changes in CD8+ and CD4+ T-cell subsets in the elderly. Hum Immunol. 2007:68:86-90.

21. Trzonkowski P, Mysliwska J, Szmit E, Wieckiewicz J, Lukaszuk K, Brydak LB, Machala M, Mysliwski A. Association between cytomegalovirus infection, enhanced proinflammatory response and low level of anti-hemagglutinins during the anti-influenza vaccination-an impact of immunosenescence. Vaccine. 2003;21:3826-36.

22. Bucci L, Ostan R, Giampieri E, Cevenini E, Pini E, Scurti M, Vescovini R, Sansoni P, Caruso C, Mari D, et al. Immune parameters identify Italian centenarians with a longer five-year survival independent of their health and functional status. Exp Gerontol. 2014;54:14-20.

23. van de Berg PJ, Yong SL, Remmerswaal EB, van Lier RA, ten Berge IJ. Cytomegalovirus-induced effector T cells cause endothelial cell damage. Clin Vaccine Immunol. 2012;19:772-9.

24. Pachnio A, Ciaurriz M, Begum J, Lal N, Zuo J, Beggs A, Moss P. Cytomegalovirus infection leads to development of high frequencies of cytotoxic virus-specific CD4+ T cells targeted to vascular endothelium. PLoS Pathog. 2016;12:e1005832.

25. Foley RN, Parfrey PS, Sarnak MJ. Epidemiology of cardiovascular disease in chronic renal disease. J Am Soc Nephrol. 1998;9:S16-23.

26. Rayner HC, Pisoni RL, Bommer J, Canaud B, Hecking E, Locatelli F, Piera L, Bragg-Gresham JL, Feldman HI, Goodkin DA, et al. Mortality and hospitalization in haemodialysis patients in five European countries: results from the Dialysis outcomes and practice patterns study (DOPPS). Nephrol Dial Transplant. 2004;19:108-20.

27. Longenecker JC, Coresh J, Powe NR, Levey AS, Fink NE, Martin A, Klag MJ. Traditional cardiovascular disease risk factors in dialysis patients compared with the general population: the CHOICE study. J Am Soc Nephrol. 2002;13:1918-27.

28. Betjes MG, Huisman M, Weimar W, Litjens NH. Expansion of cytolytic CD4 +CD28- T cells in end-stage renal disease. Kidney Int. 2008;74:760-7.

29. Betjes MG, Litjens NH, Zietse R. Seropositivity for cytomegalovirus in patients with end-stage renal disease is strongly associated with atherosclerotic disease. Nephrol Dial Transplant. 2007;22:3298-303.

30. Zawada AM, Rogacev KS, Schirmer SH, Sester M, Bohm M, Fliser D, Heine GH. Monocyte heterogeneity in human cardiovascular disease. Immunobiology. 2012;217:1273-84.

31. Kooman JP, Kotanko P, Schols AM, Shiels PG, Stenvinkel P. Chronic kidney disease and premature ageing. Nat Rev Nephrol. 2014;10:732-42.

32. Rogacev KS, Seiler S, Zawada AM, Reichart B, Herath E, Roth D, Ulrich C, Fliser D, Heine GH. CD14++CD16+ monocytes and cardiovascular outcome in patients with chronic kidney disease. Eur Heart J. 2010;32:84-92.

33. Andersson J, Libby P, Hansson GK. Adaptive immunity and atherosclerosis. Clin Immunol. 2009;134:33-46.

34. Ammirati E, Cianflone D, Vecchio V, Banfi M, Vermi AC, De Metrio M, Grigore L, Pellegatta F, Pirillo A, Garlaschelli K, et al. Effector memory T cells are associated with atherosclerosis in humans and animal models. J Am Heart Assoc. 2012;1:27-41.

35. Vasto S, Colonna-Romano G, Larbi A, Wikby A, Caruso C, Pawelec G. Role of persistent CMV infection in configuring T cell immunity in the elderly. Immun Ageing. 2007;4:2.

36. Derhovanessian E, Maier AB, Hahnel K, Beck R, de Craen AJ, Slagboom EP, Westendorp RG, Pawelec G. Infection with cytomegalovirus but not herpes simplex virus induces the accumulation of late-differentiated CD4+ and CD8 + T-cells in humans. J Gen Virol. 2011;92:2746-56.

37. Ji YN, An L, Zhan P, Chen XH. Cytomegalovirus infection and coronary heart disease risk: a meta-analysis. Mol Biol Rep. 2012;39:6537-46.

38. Muhlestein JB, Horne BD, Carlquist JF, Madsen TE, Bair TL, Pearson RR, Anderson JL. Cytomegalovirus seropositivity and C-reactive protein have independent and combined predictive value for mortality in patients with angiographically demonstrated coronary artery disease. Circulation. 2000;102:1917-23.

39. Chiu YL, Lin CH, Sung BY, Chuang YF, Schneck JP, Kern F, Pawelec G, Wang GC. Cytotoxic polyfunctionality maturation of cytomegalovirus-pp65-specific CD4 + and CD8 + T-cell responses in older adults positively correlates with response size. Sci Rep. 2016;6:19227.

40. Savva G, Pachnio A, Kaul B, Morgan K, Huppert F, Brayne C, Moss P. Cytomegalovirus infection is associated with increased mortality in the older population. Aging Cell. 2013;12(3):381-7.

41. Stenvinkel P. Inflammation in end-stage renal failure: could it be treated? Nephrol Dial Transplant. 2002;17(Suppl 8):33-8. discussion 40 
42. Blankenberg S, Rupprecht HJ, Bickel C, Espinola-Klein C, Rippin G, Hafner G, Ossendorf M, Steinhagen K, Meyer J. Cytomegalovirus infection with interleukin-6 response predicts cardiac mortality in patients with coronary artery disease. Circulation. 2001:103:2915-21.

43. Cantisan S, Torre-Cisneros J, Lara R, Zarraga S, Montejo M, Solana R. Impact of cytomegalovirus on early immunosenescence of CD8+ T lymphocytes after solid organ transplantation. J Gerontol A Biol Sci Med Sci. 2013;68:1-5.

44. Litjens NH, de Wit EA, Betjes MG. Differential effects of age, cytomegalovirus-seropositivity and end-stage renal disease (ESRD) on circulating T lymphocyte subsets. Immun Ageing. 2011;8:2.

45. Huang L, Langerak AW, Wolvers-Tettero IL, Meijers RW, Baan CC, Litjens NH, Betjes MG. End stage renal disease patients have a skewed T cell receptor Vbeta repertoire. Immun Ageing. 2015;12:28.

46. Hagiwara N, Toyoda K, Inoue T, Shimada H, Ibayashi S, lida M, Okada Y. Lack of association between infectious burden and carotid atherosclerosis in Japanese patients. J Stroke Cerebrovasc Dis. 2007;16:145-52.

47. Sansoni P, Vescovini R, Fagnoni FF, Akbar A, Arens R, Chiu YL, Cicin-Sain L, Dechanet-Merville J, Derhovanessian E, Ferrando-Martinez S, et al. Newadvances in CMV and immunosenescence. Exp Gerontol. 2014;55:54-62.

48. Wang GC, Dash P, McCullers JA, Doherty PC, Thomas PG. T cell receptor alphabeta diversity inversely correlates with pathogen-specific antibody levels in human cytomegalovirus infection. Sci Transl Med. 2012;4:128ra142.

49. Yu HT, Youn JC, Kim JH, Seong YJ, Park SH, Kim HC, Lee WW, Park S, Shin EC. Arterial stiffness is associated with cytomegalovirus-specific senescent CD8+ T cells. J Am Heart Assoc. 2017;6:e006535.

50. Pamukcu B, Lip GY, Devitt A, Griffiths H, Shantsila E. The role of monocytes in atherosclerotic coronary artery disease. Ann Med. 2010;42:394-403.

Ready to submit your research? Choose BMC and benefit from:

- fast, convenient online submission

- thorough peer review by experienced researchers in your field

- rapid publication on acceptance

- support for research data, including large and complex data types

- gold Open Access which fosters wider collaboration and increased citations

- maximum visibility for your research: over $100 \mathrm{M}$ website views per year

At BMC, research is always in progress.

Learn more biomedcentral.com/submissions 